\title{
INFLUENCE OF METEOROLOGICAL STORMS ON IONOSPHERIC PARAMETERS IN THE BALTIC REGION IN 2010
}

\author{
I.V. Karpov', O.P. Borchevkina ${ }^{2}$, R.Z. Dadashev², A.V. Ilminskaya ${ }^{2}$ \\ ${ }^{1}$ WD IZMIRAN, Kaliningrad, Russia; I. Kant Baltic Federal University, Kaliningrad, Russia, ivkarpov@inbox.ru \\ ${ }^{2}$ I. Kant Baltic Federal University, Kaliningrad, Russia
}

The paper presents observations of atmospheric and ionospheric parameters during strong meteorological disturbances (storms) in the Kaliningrad region. The critical frequency of the F2 layer (foF2) and the total electron content (TEC) were observed at the station Kaliningrad $\left(20^{\circ} \mathrm{E}, 54.20^{\circ} \mathrm{N}\right)$. Atmospheric pressure and wind were taken to be the atmospheric parameters under study. The analysis of ionospheric observations has shown that during meteorological storms the amplitude of diurnal variations in TEC decreases to $50 \%$; and in foF2, to $15 \%$ as compared to quiet days. The revealed changes in ionospheric conditions during meteorological storms are regularly registered and represent a characteristic feature of the meteorological effect on the ionosphere.

Keywords: Acoustic-gravity waves, ionosphere, total electron content, meteorological disturbances, storms.

\section{INTRODUCTION}

Meteorological processes are an important source of acoustic-gravity waves (AGW) in the atmosphere. Results of multiple experimental and theoretical studies suggest that different dynamic processes in the lower atmosphere and on Earth's surface, which are caused, for example, by meteorological, seismological, and other events, have a significant effect on ionospheric conditions. Assessments of the impact of such processes in the lower atmosphere on ionospheric conditions are reported in [Altadill et al., 2001; Sauli, Boska, 2001a; Lastovicka, Sauli, 1999; Fritts, Alexander, 2003]. In particular, changes in the structure of ionospheric variations during meteorological disturbances are analyzed in [Chernigovskaya et al., 2015; Sauli, Boska, 2001b; Vadas, Liu, 2009; Sindelarova et al., 2009; Polyakova, Perevalova, 2013].

Strong meteorological disturbances are characteristic of the climate of the Kaliningrad region. This allows us to identify meteorological effects in changes of ionospheric conditions.

The purpose of this paper is to study disturbances of ionospheric parameters occurring during meteorological storms and to find their features from observations made at the station Kaliningrad. 


\section{DIURNAL VARIATIONS IN ATMOSPHERIC AND IONOSPHERIC PARAMETERS DURING A METEOROLOGICAL STORM}

To examine ionospheric dynamics in conditions of meteorological disturbances, we have selected periods of the strongest meteorological storms in the Kaliningrad region.

We analyze ionospheric data, using observations of the F2 layer critical frequency $\left(f_{0} \mathrm{~F} 2\right)$ and total electron content (TEC) obtained at the station Kaliningrad. Methods of determining $f_{0} \mathrm{~F} 2$ from observations, made by the ionosonde Parus, and TEC by analyzing signals from GNSS satellites are described in [Karpenko, Manaenkova, 1996; Baran et al., 1997]. Data on meteorological conditions have been taken from www.rp5.ru.

This paper focuses on rapidly growing meteorological disturbances followed by high winds of force 6-8 on the Beaufort scale. Such storms in the Kaliningrad region generally last less than two days. To identify characteristic features of ionospheric disturbances arising during the meteorological disturbances, we consider an observation period that began five days before a storm and ended five days after it. As weather parameters, we analyze diurnal variations in atmospheric pressure $P_{0}$ at the altitude of the station and maximum gusts of wind at an altitude of $10 \mathrm{~m}$ over a 3-hour period between observations - the parameter FF3. To minimize the influence of geomagnetic factors on ionospheric variations, we chose meteorological disturbances under quiet geomagnetic conditions.

Figure 1 presents observations of atmospheric and ionospheric parameters during a meteorological storm in December 2010. Geomagnetic conditions on December 6-12 were relatively quiet; the $K_{\mathrm{p}}$ index was less than 3. During the storm on December $9-10, K_{\mathrm{p}} \leq 1$. Solar activity over that period was also low, $F_{10.7}=84$. Referring to Figure 1, the period of lower atmospheric pressure lasted from December 4 to 12 (Figure 1,a). Winds in the surface layer got up during the initial phase of the atmospheric pressure decrease, especially noticeably on December 9-10 with the wind speed as high as $13 \mathrm{~m} / \mathrm{s}$ (Figure 1, b). The distinguished periods of changes in weather parameters are clearly seen in ionospheric variations. Thus, for example, the amplitude of TEC variations (Figure 1, c) on December 4-5 and 9-10 decreased to $\sim 30-40 \%$ for daytime and $\sim 50 \%$ for nighttime as compared to stormless days.

In the $f_{\mathrm{o}} \mathrm{F} 2$ variations (Figure $1, d$ ), the changes are less pronounced, but during the storm $f_{\mathrm{o}} \mathrm{F} 2$ decreased to $\sim 15 \%$. 

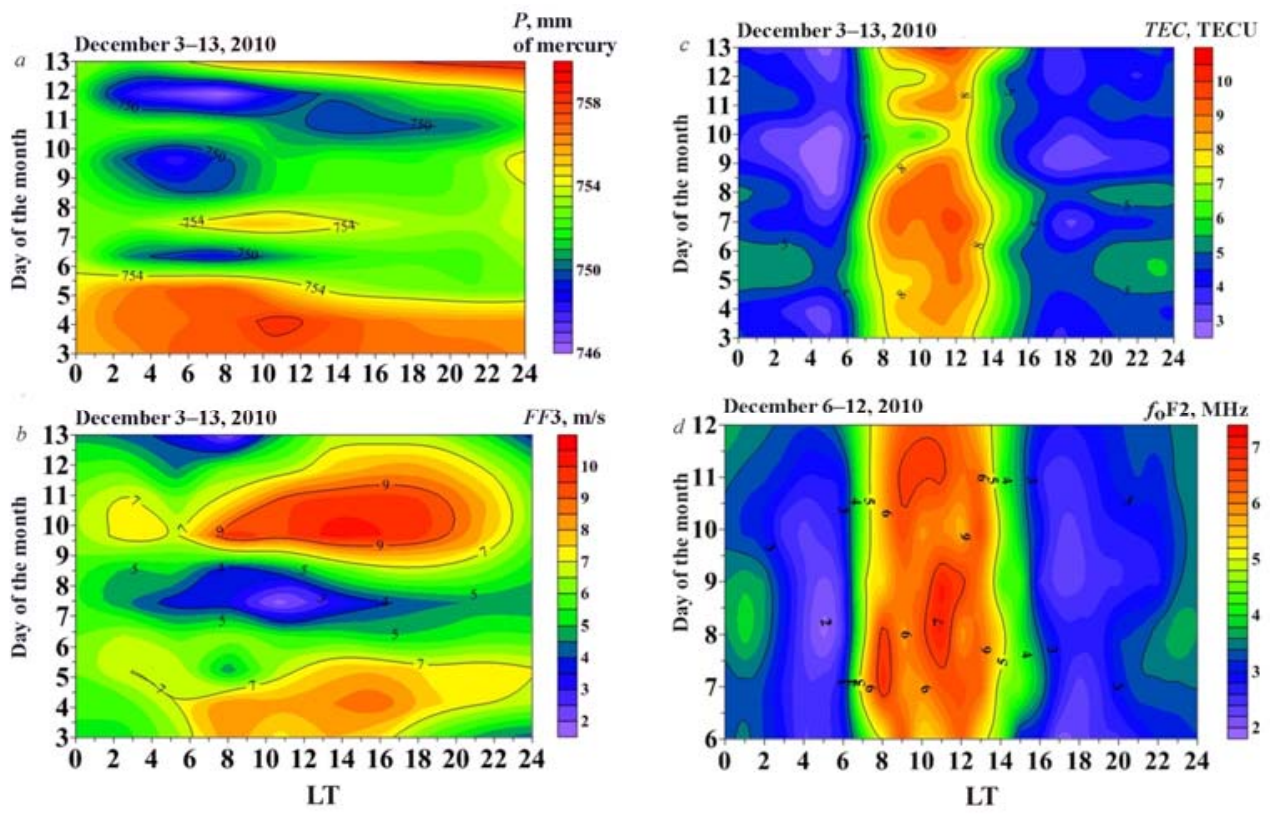

Figure 1. Diurnal pressure variations on December 3-13, 2010 as deduced from observations made at the station Kaliningrad $(a)$; diurnal wind speed variations $(b)$; diurnal TEC variations $(c)$; diurnal $f_{\mathrm{o}} \mathrm{F} 2$ variations on December 6-12, $2010(d)$

Figure 2 illustrates variations in atmospheric and ionospheric parameters during a meteorological disturbance of August 18, 2010. Note that storms in the Kaliningrad region occur much more rarely in summer than in other seasons. On August 13-23, geomagnetic conditions were quiet; $K_{\mathrm{p}} \leq 3$. Solar activity changed very little, decreasing from $F 10.7=86$ on August 13 to $F 10.7=76$ on August 23.
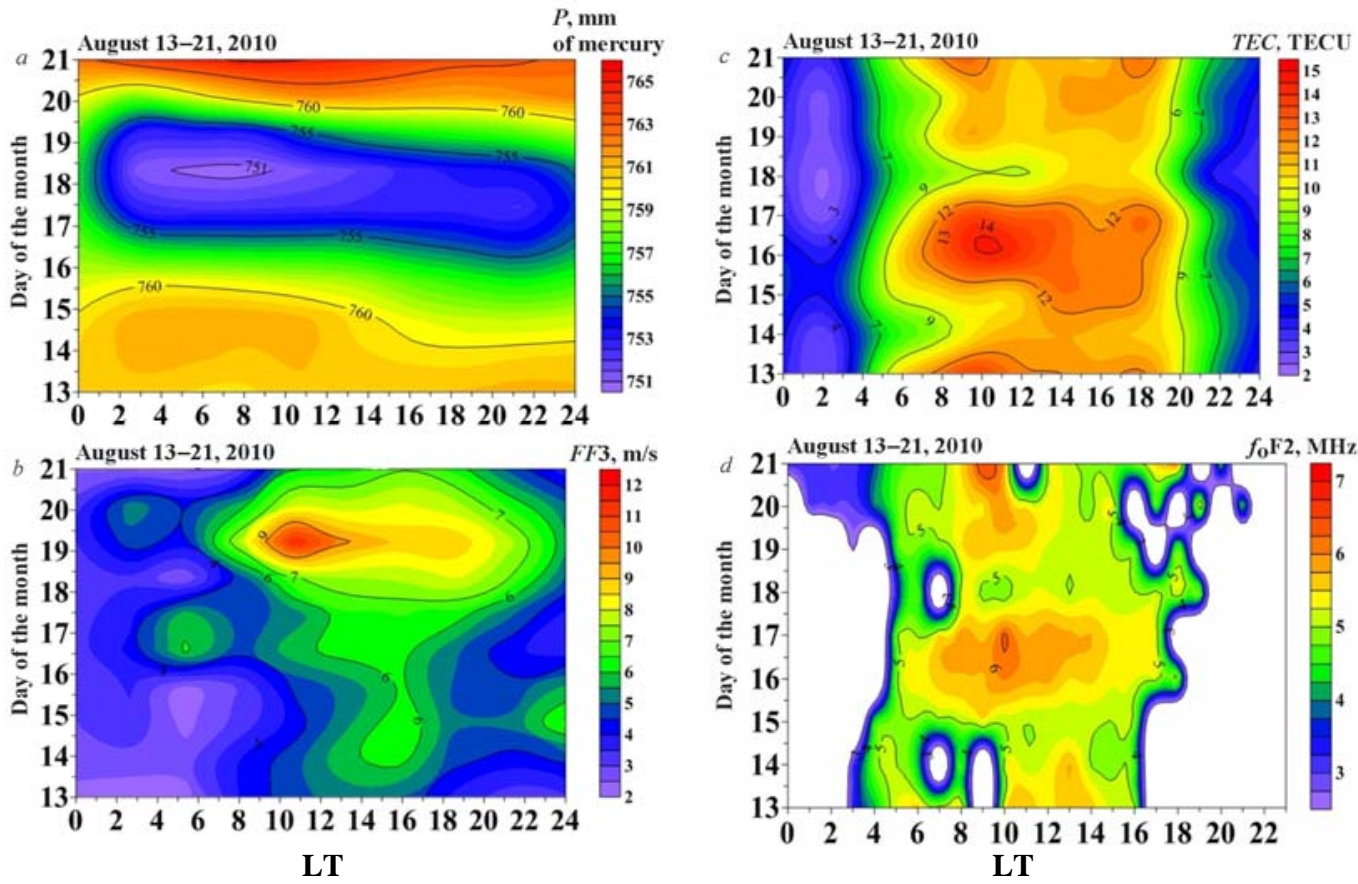

Figure 2. Diurnal variations in surface air pressure (a); diurnal wind speed variations (b); diurnal TEC variations $(c)$; diurnal $f_{0} \mathrm{~F} 2$ variations $(d)$ on August 13-21, 2010 according to observations from the station Kaliningrad 
It is apparent that atmospheric pressure began to drop on August 14, reached its minimum on August 18, on the day of the storm, and began to rise on August 20 (Figure 2, a). The wind speed during the observation period increased largely during daytime on August 18-19, reaching its peak values of $\sim 14 \mathrm{~m} / \mathrm{s}$ on August 19 . Figure $2 c, d$ shows that TEC and $f_{\mathrm{o}} \mathrm{F} 2$ disturbances were pronounced on August 14 and 18 (the white color in Figure 2, $d$ indicates observation areas in which we failed to find critical frequency values owing to strong absorption in the $\mathrm{E}$ and $\mathrm{D}$ regions). Those days, decreases in daytime TEC values run to $\sim 30-40 \%$ and in the critical frequency, to $\sim 15-20 \%$ as compared to stormless days.

Of 2008-2010 observations we have selected eight meteorological storms that occurred under quiet geomagnetic conditions. The analysis of the ionospheric observations made during such periods has shown that ionospheric electron density decreases similar to those shown in Figure 1, 2 are steadily observed. Since the analysis of ionospheric disturbances relied only on geomagnetically quiet periods, we can assume that this ionospheric response was caused by atmospheric disturbances during the meteorological storm. However, the data on atmospheric pressure and wind speed variations we present in this paper probably do not exhaust the set of meteorological parameters characterizing storm conditions and predetermining the ionospheric response. We may note, for example, that in winter (Figure 1) the ionospheric response largely reflected wind speed dynamics; in summer (Figure 2), atmospheric pressure dynamics.

Studying relationships between meteorological processes and the ionosphere is a difficult task, and it should be continued to identify meteorological factors responsible for these relationships.

Note also that the ionosphere responds to wind (Figure 1) and pressure (Figure 2) disturbances fairly quickly, within several hours ( $\sim 3-6 \mathrm{hr})$. It is natural to assume that the most likely carrier of meteorological disturbance energy to the upper atmosphere is AGW. Experimental observations of wave ionospheric variations during intense cyclonic activity have revealed TEC variations having periods of infrasound and gravity waves (2-20 min) [Polyakova, Perevalova, 2013].

We can suppose that rapid changes in meteorological conditions during a storm favor excitation of AGWs over a wide range of periods. Propagation of AGWs to the upper atmosphere and their dissipation there result in the observed ionospheric disturbances. Theoretical studies of AGW propagation from sources in the lower atmosphere suggest that waves of this range can quickly reach the upper atmosphere and due to dissipation can give rise to large-scale disturbances, specifically to local heating regions. Noticeable large-scale disturbances in the upper atmosphere conditioned by dissipation of AGWs propagating from a source in the lower atmosphere are observed 1-2 hr after activation of the source [Karpov, Kshevetsky, 2014]. A local heating region appearing in the upper atmosphere should affect the ionization balance in the ionosphere and lead to a decrease in the ionospheric electron density due to the growing influence of recombination processes.

\section{CONCLUSIONS}

The analysis of the observations of ionospheric parameters made at the station Kaliningrad has shown that during meteorological storms there are considerable decreases in TEC and F-layer critical 
frequency, especially noticeable during daylight hours. Decreases in TEC run to $50 \%$ and in $f_{0} \mathrm{~F} 2$, to $\sim 15 \%$ as compared to quiet days. Such ionospheric disturbances steadily occur during meteorological storms. This allows us to consider the revealed ionospheric disturbances as typical signs of disturbances driven by meteorological processes.

Ionospheric disturbances develop quite rapidly, within several hours after meteorological disturbances. It is conceivable that physical mechanisms implementing this relationship are determined by AGW propagation.

The study was funded by the Russian Foundation of Fundamental Research No. 15-05-01665 and by the project of the Ministry of Education and Science of the Russian Federation No. 3.1127.2014/K.

\section{REFERENCES}

Altadill D., Apostolov E.M., Solé J.G., Jacobi Ch. Origin and development of vertical propagating oscillations with periods of planetary waves in the ionospheric F region. Physics and Chemistry of the Earth, Part C: Solar, Terrestrial \& Planetary Sci. 2001, vol. 26, iss. 6, pp. 387-393. DOI: 10.1016/S1464-1917(01)00019-8.

Baran L.W., Shagimuratov I.I., Tepenitzina N.J. The Use of GPS for Ionospheric Studies. Artificial satellites. J. Planetary Geodesy. 1997, vol. 32, no. 1, pp. 49-60.

Chernigovskaya M.A., Shpynev B.G., Ratovsky K.G. Meteorological effects of ionospheric disturbances from vertical radio sounding data. J. Atmospheric and Solar-Terrestrial Phys. 2015, vol. 11, iss. 22, pp. $235-243$. DOI: 10.1016/j.jastp.2015.07.006.

Fritts, D.C., Alexander M.J. Gravity wave dynamics and effects in the middle atmosphere. Rev. of Geophys. 2003, vol. 41, is.1, pp. 3-64. DOI: 10.1029/2001RG000106.

Karpenko, A.L., Manaenkova, N.I. Nonlinear time series analysis of the ionospheric measurements Geologishe Rundshau. 1996, vol. 85, no. 1, pp. 124-129.

Karpov I. V., Kshevetskii S. P. Formation of Large Scale Disturbances in the Upper Atmosphere Caused by Acoustic Gravity wave Sources on the Earth's Surface. Geomagnetism and Aeronomy. 2014, vol. 54, no. 4, pp. 553-562. DOI: $10.1134 / \mathrm{S} 0016793214040173$.

Lastovicka J., Sauli P. Are planetary wave type oscillations in the F2 region caused by planetary wave modulation of upward propagating tides? Advances in Space Research. 1999, vol. 24, iss. 11, pp. 1473-1476. DOI: 10.1016/S0273-1177(99)00708-5.

Polyakova A.S., Perevalova N.P. Comparative analysis of TEC disturbances over tropical cyclone zones in the north-west Pacific ocean. Adv. in Space Res. (includes Cospar Information Bulletin). 2013. vol. 52, iss. 8, pp. 1416-1426. DOI: 10.1016/j.asr.2013.07.029.

Sauli P., Boska J. Observations of Gravity Waves of Meteorological Origin in the F-Region Ionosphere. Physics and Chemistry of the Earth, Part C: Solar, Terrestrial \& Planetary Sci. 2001, vol. 26, iss. 6, pp. 425-428. DOI: 10.1016/S1464-1917(01)00024-1.

Sauli P., Boska J. Tropospheric events and possible related gravity wave activity effects on the ionosphere. J. Atmospheric and Solar-Terrestrial Phys. 2001, vol. 63, iss. 9, pp. 945-950. DOI: 10.1016/S1364-6826(00)00205-4.

Sindelarova T., Buresova D., Chum J., Hruska F. Doppler observations of infrasonic waves of meteorological origin at ionospheric heights. Adv. in Space Res. 2009, vol. 43, pp. 1644-1651. DOI: 10.1016/j.asr.2008.08.022; 2009.

Vadas S.L., Liu H.-L. Generation of large-scale gravity waves and neutral winds in the thermosphere from the dissipation of convectively generated gravity waves. J. of Geophys. Res: Space Phys. 2009, vol. 114, A10310. DOI: 10.1029/2009JA014108.

http://www.rp5.ru 